The effect of input-based practice on the accurate and speedy performance of EFL refusals: The role of proficiency and lexical access ability in focus

Shirinbakhsh, Salva $\$
University of Isfahan, Iran (salvashirinbakhsh@gmail.com)

Eslami Rasekh, Abbass

University of Isfahan, Iran (abbasseslamirasekh@yahoo.com)

Tavakoli, Mansoor

University of Isfahan, Iran (Mr.tavakoli14@gmail.com)

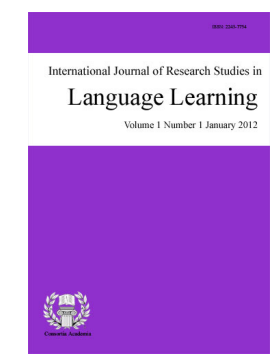

ISSN: 2243-7754 Online ISSN: 2243-7762

OPEN ACCESS

\begin{tabular}{lll}
$\begin{array}{l}\text { Received: } 18 \text { August } 2015 \\
\text { Available Online: 2 November 2015 }\end{array}$ & $\begin{array}{l}\text { Revised: 7 September 2015 } \\
\text { DOI: 10.5861/ijrsll.2015.1318 }\end{array}$ & Accepted: 30 September 2015 \\
\hline
\end{tabular}

\title{
Abstract
}

This study examined the effect of input-based practice on the development of the accurate and speedy recognition and production of English refusals among Iranian EFL learners. It was, also, interested in the possible role of general language proficiency and lexical access ability as a cognitive skill on the enhancement of pragmatic accuracy and speed. Seventy-six Persian learners of English were assigned to either input-based or control group. Before the treatment, a lexical access test and a proficiency test were taken. After a five- session treatment, a Pragmatic Listening Judgment Test (PLJT) and an Oral Discourse Completion Test (ODCT) were run. The results indicated the positive effect of input-based practice in speedy recognition and accurate production of English refusals. In addition, general L2 proficiency and lexical access ability correlated significantly with the pragmatic accuracy and pragmatic speed of the learners, respectively, both in the recognition and production of English refusals.

Keywords: recognition; production; refusal; skill acquisition; ACT-R model 


\section{The effect of input-based practice on the accurate and speedy performance of EFL refusals: The role of proficiency and lexical access ability in focus}

\section{Introduction}

Pragmatic competence is defined as the acquisition of its knowledge as well as the achievement of automatic processing ability (Kasper, 2001). Pragmatic accuracy (knowledge) and pragmatic processing ability (speed) have been proved to be completely distinct; they, also, follow diverse developmental pattern (Li \& Taguchi, 2014). Pragmatic accuracy needs pragmalinguistic and sociopragmatic knowledge to develop. Specifically, the knowledge of using appropriate linguistic forms in appropriate social contexts in order to convey the intended meaning (form-function-context mappings (Schmidt, 1993). However, the development of pragmatic speed depends on the automatization of control strategies by means of repetitions in pragmatic performance ( $\mathrm{Li} \&$ Taguchi, 2014). In other words, pragmatic speed is the result of the proceduralizarion of declarative knowledge (the knowledge of 'what') through repetitive practice. This notion is well developed in the Anderson's (1983) cognitive theory of skill development: the ACT-R (adaptive control of thought-rational) model. The model defines cognitive skill development in three stages: in the first stage learners are presented with factual knowledge and rules (declarative knowledge). Their performance indicate high rate of error. This is called cognitive stage. In the next stage, learners go through the repetitive and extensive practices. The result would be the proceduralization of declarative knowledge which embodies in faster performance and less errors. This is called associative stage. The last stage, autonomous, provides the automatic and error free performance of learners.

Investigating the potentials of this model for pragmatic development has been recently begun. There are few studies which have focused on practice in the sense of skill acquisition for pragmatic instruction (Li \& Taguchi, 2014; Li, 2012). Therefore, more future research in this regard awaits. In a recent study, Li and Taguchi (2014) investigated the effect of practice modality (input-based and output-based) on pragmatic accuracy and speed of Chinese request forms. They used three groups, namely: input-based, out-put based and control group. The two treatment groups, input-based and output-based, practiced the target request forms in four consecutive days while the control group had no practice. The results, measured by a Listening Judgment Test (LJT) and an Oral Discourse Completion Test (ODCT), indicated that input-based and output-based groups were successful in comprehension and production tests, respectively. That is, their pragmatic accuracy was shared across the two skills; however, the pragmatic speed was dependent on the specific practice each group received.

To examine the effect of practice in accurate and speedy pragmatic recognition and oral production, $\mathrm{Li}$ (2012) employed ACT-R model in the instruction of Chinese request forms. In his practice, learners were assigned to two experimental groups: an intensive training group and a regular training group, in addition to a control group. The three groups were given explicit metapragmatic information about the pragmatic target. Then only the experimental groups were provided with repetitive structured input practices which comprised of referential and affective activities. These activities aimed at fortifying pragmatic form-function-context mappings. In other words, these practices had the intention of transiting declarative knowledge of Chinese request to procedural knowledge. The intensive training group encountered the pragmatic target twice as much as the regular training group. To measure pragmatic accuracy and speed, a Pragmatic Listening Judgment Task (PLJT) and an Oral Discourse Completion Task (ODCT) were used. The results displayed the effectiveness of input-based practice in promoting learners' speed in the listening task and learners' accuracy in the oral production task.

In spite of his great contribution to the field of pragmatic instruction, there were some gaps in Li's (2012) study. First, his intensive training group had only two practice sessions. Considering the documented beneficial effect of distributed practice over time (Seabrook \& Solity, 2005), these sessions might not be enough. This 
could be the reason why the skill based practice was not able to show its full effect in accurate and speedy pragmatic recognition and production of Chinese request. Second, it seemed the control group in Li's study had some pre-knowledge about the target pragmatic feature under study since their pretest scores were similar to their posttests' results. Third and finally, none of the groups could succeed in the recognition of accurate request forms. As Taguchi (2011) mentioned this could be due to a ceiling effect. That is the explicit instruction was enough for major learning; therefore, it leaves little room for practice to improve learners' knowledge. This line of research could be further refined by covering these gaps.

Furthermore, a few recent studies have indicated the impact that underlying factors may have on pragmatic speed performance. For example, Taguchi (2005) examined the effect of proficiency on pragmatic speed comprehension and found no significant result. However, Segalowitz and Freed (2004) revealed that higher proficiency among Spanish learners leads to faster lexical access ability and therefore faster performance. In other words, proficiency level of learners is related to overall performance speed. Therefore, more studies are needed for understanding the relation between proficiency and performance speed.

Contributing directly to performance speed, lexical access ability has been largely studied in different fields of skill development; for example in vocabulary development (Poulin-Dubois, Bialystok, Blaye, Polonia, \& Yott, 2013), translation studies (Francis, Tokowicz, \& Kroll, 2014), sign language (Gutiérrez, Müller, Baus, \& Carreiras, 2012), general oral fluency (Segalowitz \& Freed, 2004). Nonetheless, very few studies have examined lexical access ability-the process of form-meaning connections- in pragmatic comprehension (e.g., Taguchi, 2007) and even scarcer studies have addressed lexical access ability in both pragmatic accuracy and speed.

In general, the employment of ACT-R model in the development of pragmatic performance is new and very little research has addressed it (Li, 2012; Li \& Taguchi, 2014). Furthermore, research examining the effect of proficiency and lexical access ability on both pragmatic comprehension and production is scarce. Considering the gaps in the existing literature, this study aimed to understand the effect input-based practice (which is based on ACT-R model) may have on the accurate and speedy pragmatic performance of Iraninan EFL learners in English refusals. Specifically, this study, also, investigates the underlying role of language proficiency and lexical access ability in pragmatic recognition and production. Overall, the following research questions guide the study:

$>$ Does input-based practice have any effect on the pragmatic accuracy and speed of Iranian EFL learners' recognition and oral production of English refusals?

$>$ To what extent are proficiency and lexical access ability related to the pragmatic accuracy and speed of Iranian EFL learners' recognition and oral production of English refusals?

\section{Method}

\subsection{Design}

Adopting a quasi-experimental design, this study tries to highlight the effect of input-based practice on the accurate and speedy refusals among EFL learners. The study follows pretest-treatment-posttest-delayed posttest structure using a control group. Three independent variables include first, input-based practice, second, proficiency and third, lexical access ability. The two dependent variables are the accurate and speedy refusals of EFL learners. The accuracy is rated according to a six-point scale introduced by Taguchi (2013) and the pragmatic speed is measured by a pragmatic listening judgment task (PLJT) and an oral discourse complete task (ODCT). 


\subsection{Participants}

The participants of this study include 72 first-year students of Teaching English as a Foreign Language (TEFL) in Sheikh Bahaee University in Isfahan, Iran. They were all female with the age range between 19 to 24 years. They comprised two intact classes as one experimental group (input-based practice, 35 students) and one control group (37 students). The participants had no experience of travelling to English speaking countries. They, also, passed their university prerequisite for meeting an acceptable level of English language proficiency.

\subsection{Data collection methods}

\subsubsection{Instruments for pedagogical treatment}

Input-based group: The five-session treatment was adapted from Li (2012). In the first session, learners were provided with metapragmatic instruction on the pragmalinguistic and sociopragmatic features of speech act of refusals. They were also shown different refusal strategies (Salazar Campillo, Safont Jordà, \& Codina Espurz, 2009, Appendix A) and the way they are formed and expressed in English by powerpoint. After the explanation, in order to be assured that learners earned the required declarative knowledge, their knowledge was assessed by an interactive six-item written DCT (adapted from Al-Issa, 2003; Beebe, Takahashi, \& Uliss-Weltz, 1990; Ebsworth \& Kodama, 2011; Umale, 2011, Appendix B). The results showed an appropriateness rate of 100\% in all their responses. That is they could answer all the DCT situations by appropriate refusal strategies. This stage indicated that the participants became qualified enough for practice sessions.

In the practice sessions learners were provided with two types of activities: referential and affective ( $\mathrm{Li}$, 2012). They had to exercise form-function-context mappings in referential activities and rate the appropriateness of refusal responses in affective activities. As Wong (2004) mentioned these activities are necessary in process instruction (PI). In the four following practice sessions, the learners worked on four situations on each session (worksheets 1,2,3,4, Appendix C). The situations composed of two referential activities in which learner had to decide upon the appropriateness of refusals and specify their social variables such as power and social distance. They, also, had to provide reasons for their answers. The learners were not allowed to go to the next activities, the affective activities, unless their choices were verified by the teacher. In the next two affective activities, the learners were supposed to rate three refusals on a 5-point scale: from 1 as "very inappropriate" to 5 as "very appropriate". In general, during four practice sessions, the learners practiced 16 refusal examples.

\subsubsection{Instruments for data collection}

Pragmatic accuracy and speed - To measure the learners' accurate and speedy recognition of refusals, a Pragmatic Listening Judgment Task (PLJT, Appendix D) was conducted in three times: pre-, post- and delayed posttests. It was adapted from Beebe, Takahashi, and Uliss-Weltz, 1990; Chen, 1996; Umale, 2011, and Uso-Juan, 2013. It consisted of 15 refusal situations: 2 invitations, 4 suggestions, 4 offers, and 5 requests. The situations were presented on a computer screen. Learners had to read the situations and choose one of the following choices: A. Pragmatically appropriate and grammatically accurate, B. Pragmatically inappropriate and grammatically accurate and C. Pragmatically appropriate and grammatically inaccurate. The accuracy was defined as the number of correct choices learners made with a score range of 0 to 15 (15 PLJT items X 1 point per correct answer) and the pragmatic speed was defined as the average number of seconds it took to choose the correct choices.

In addition, to measure the learners' accurate and speedy production of refusals, an Oral Discourse Completion Task (ODCT, Appendix E) was administered in pre-, post- and delayed posttests. It had eight situations which were adapted from Usó-Juan (2013) and Hashemian (2012). A detailed description of the situations regarding the context, participants' descriptions, social status and social distance is presented in the following table. 
The effect of input-based practice on the accurate and speedy performance of EFL refusals

\section{Table 1}

Variable descriptions in the Oral Discourse Complete Task (ODCT)

\begin{tabular}{|c|c|c|c|c|}
\hline Sit. & Contextual setting & Participants' roles & Social status & Social distance \\
\hline 1 & University & $\begin{array}{l}\text { Student refuses lending his/her class } \\
\text { notes to another student }\end{array}$ & Equal & Acquaintance \\
\hline 2 & Cafeteria & $\begin{array}{l}\text { Research student refuses giving the } \\
\text { exact amount of money to a } \\
\text { waitress }\end{array}$ & Low & Stranger \\
\hline 3 & University & $\begin{array}{l}\text { Student refuses leaving the } \\
\text { classroom (interacting with a } \\
\text { Professor) }\end{array}$ & High & Acquaintance \\
\hline 4 & University & $\begin{array}{l}\text { Student refuses lending his/her car } \\
\text { to another student }\end{array}$ & Equal & Stranger \\
\hline 5 & University & $\begin{array}{l}\text { Research student refuses fixing the } \\
\text { laptop from a first-year student }\end{array}$ & Low & Intimate \\
\hline 6 & Butcher's & $\begin{array}{l}\text { Student refuses wearing plastic } \\
\text { gloves (interacting with a woman } \\
\text { from the town hall) }\end{array}$ & High & Stranger \\
\hline 7 & University & $\begin{array}{l}\text { Research assistant refuses leaving a } \\
\text { document in the library (interacting } \\
\text { with the secretary of the } \\
\text { department) }\end{array}$ & Low & Acquaintance \\
\hline 8 & University & $\begin{array}{l}\text { Research assistant refuses helping a } \\
\text { Professor finishing an online } \\
\text { questionnaire }\end{array}$ & High & Intimate \\
\hline
\end{tabular}

In this section, the learners were measured one by one. The researcher read the situations to them. Meantime, they hold a written description of the situations. Upon finishing the reading and hearing a signal sound, the learners were supposed to look up and answer orally to the situation. Their time was measured. This process was replicated for each ODCT situation. The pragmatic speed was measured by the average number of words per minute when the learners refuse appropriately in the situations. The pragmatic accuracy was measured by Taguchi's (2013) six-point rating scale. The accuracy ranges from 0 to 40 (8 ODCT items x 5 points per item). The description of rating scale is in appendix F. All the test items the learners encountered in PLJT and ODCT were new and they did not practice with them during treatment time.

Proficiency - To assess the relationship between proficiency of the language learners on one hand and the pragmatic performance speed and accuracy on the other hand, an OPT (Oxford Placement Test) version one was run one week before the pretest. The test consisted of 60 items consisted of vocabulary (20 items), grammar (20 items) and reading comprehension (20 items). The learners completed it in 90 minutes. They were divided into low or high proficiency groups based on their OPT results. Those with 22 and below scores fell within the low-level range and those with 38 and above fell within the high-level range. The learners whose score fell in the middle of range (OPT scores, 23-37) were not taken into account.

Lexical Access Test - To seek the correlation between learners' cognitive processing skill and the two aspects of pragmatics, speed and accuracy, a lexical access test (LAT) in the form of animacy judgement task was administered two days before the pretest. LAT measured learners' cognitive speed in categorizing each single word. This computerized test (Appendix G) consisted of 80 high frequent English words taken from Segalowitz and Freed (2004). The words appeared on a computer screen and learners had to decide whether the word referred to an animate or non-animate object. For example 'bird' is animate and 'car' is non-animate.

To do the test, learners first read the instruction in their native language. Then, they completed three practice items. Finally, they started the 80-word LAT. The words appeared on the computer screen one by one and learners had to choose whether the word referred to a living or nonliving object. When they made their choice, the computer automatically showed the next item. Learners' performance from the beginning of the test to the end was recorded and timed. 


\subsection{Procedure}

The two intact classes served as treatment and control groups. The classes met two times a week with duration of 90 minutes. Before the start of the treatment, the proficiency and lexical access ability (LAT) of learners were assessed. One week before the treatment learners completed the pretests. One week after the treatment and two weeks afterwards, posttests and delayed posttest were administered. During test times, first a pragmatic listening judgment task (PLJT) (adapted from Beebe et al., 1990; Chen, 1996; Umale, 2011; Usó-Juan, 2013) and then an oral discourse complete task (ODCT) adapted from Usó-Juan (2013) and Hashemian (2012) were employed. The treatment lasted for five sessions and the control group experienced no treatment.

\section{Results}

As stated earlier, this study sought to investigate the effect of input-based practice on the development of the accurate and speedy recognition and production of English refusals among Iranian EFL learners. In addition, the current study tried to examine the extent to which participants' proficiency and lexical access ability were related to the pragmatic accuracy and speed of their recognition and oral production of English refusals. In order to reach these aims several statistical tests were performed using SPSS (ver. 22) which are reported below.

\subsection{Development of pragmatic accuracy}

In order to examine the first research question, a series of repeated measures ANOVAs were run with time (1, 2 , and 3) as the within-group variable. The descriptive data of the accuracy scores from the PLJT and ODCT in the pretest, immediate posttest, and delayed posttest are presented in Table 2. Visual representations of the pragmatic accuracy scores are also illustrated in Figure 1 and 2.

\section{Table 2}

Descriptive statistics of the accuracy scores

\begin{tabular}{|c|c|c|c|c|c|c|c|c|}
\hline \multirow[t]{2}{*}{ Instrument } & \multirow[t]{2}{*}{ Group } & \multirow[b]{2}{*}{$\mathrm{N}$} & \multicolumn{2}{|c|}{ Pretest (1) } & \multicolumn{2}{|c|}{ Posttest (2) } & \multicolumn{2}{|c|}{ Delayed posttest (3) } \\
\hline & & & $\mathrm{M}$ & $\mathrm{SD}$ & $\mathrm{M}$ & SD & $\mathrm{M}$ & $\mathrm{SD}$ \\
\hline \multirow{2}{*}{$\begin{array}{l}\text { PLJT } \\
\text { (Recognition) }\end{array}$} & Experimental & 35 & 7.19 & 9.54 & 8.21 & 10.64 & 8.32 & 11.74 \\
\hline & Control & 37 & 6.82 & 10.68 & 7.21 & 11.96 & 8.11 & 11.13 \\
\hline \multirow{2}{*}{$\begin{array}{l}\text { ODCT } \\
\text { (Production) }\end{array}$} & Experimental & 35 & 23.54 & 9.85 & 31.49 & 11.23 & 32.05 & 12.42 \\
\hline & Control & 37 & 23.31 & 9.21 & 25.63 & 8.61 & 24.21 & 10.09 \\
\hline
\end{tabular}

Initially, one-way ANOVAs were run to check the differences in the pretests of the PLJT and ODCT accuracy scores. Results revealed no significant differences between the groups prior to the treatment $(p>.05)$. Afterwards, in order to examine the development of recognition and production accuracy scores over the three testing times, two separate one-way repeated-measures ANOVAs were conducted for each of the PLJT and ODCT instruments.

Regarding the recognition accuracy, results of the repeated measures ANOVA showed no significant improvements over the three testing periods, $F(2,35)=6.41, p>.05$. In addition, one-way ANOVAs across the two groups revealed no significant effects of the treatment, $F(2,72)=6.83, p>.05$. With respect to the production scores, repeated measures ANOVA revealed significant effects for time, $F(3,35)=14.62, p<.05$. Tukey's HSD post hoc tests indicated that there were significant improvements made by the input-based group from pretest to posttest $(p<.05)$ and also from pretest to delayed posttest $(p<.05)$. Besides, ANOVAs revealed that the input-based group performed significantly better than the control group in both the immediate, $F(2,72)$ $=9.42, p<.05$, and the delayed posttests, $F(2,72)=8.17, p<.05$. It should be noted that no significance differences were found across the three testing periods in the control group.

Consequently, based on the obtained results it could be concluded that input-based practice led to the improvement of accurate production of English refusals. However, input-based practice did not have any effects 
on the pragmatic accuracy of learners' recognition of English refusals.

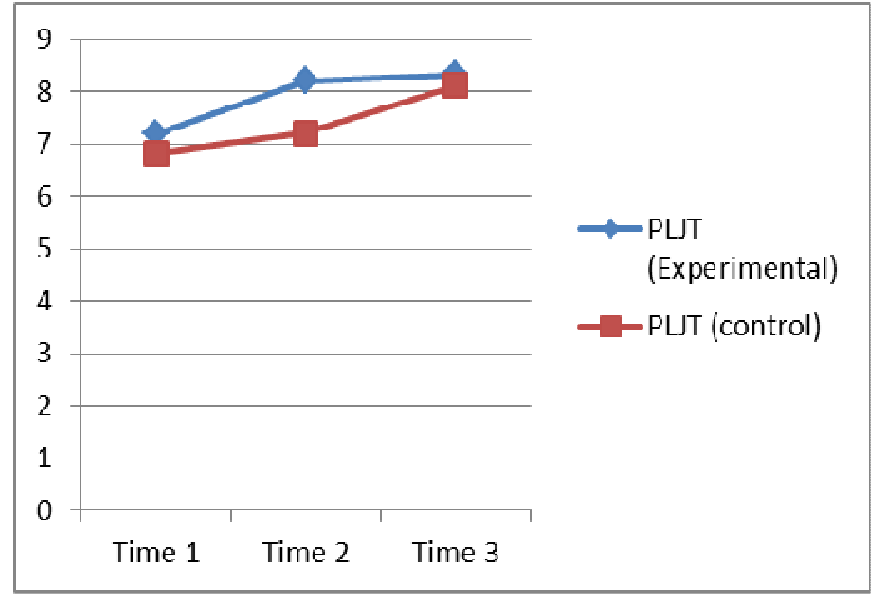

Figure 1. Development of the accuracy of Recognition

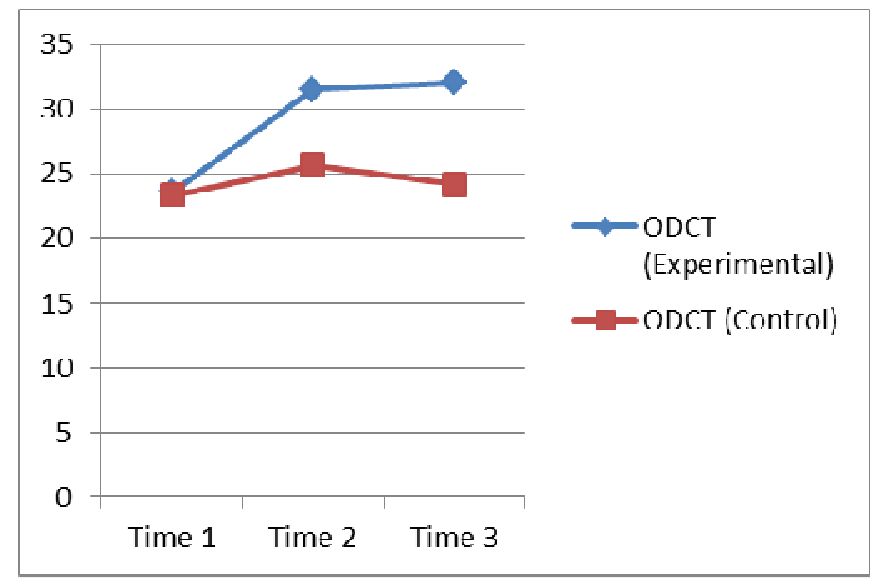

Figure 2. Development of the accuracy of Production

\subsection{Development of pragmatic speed}

The second research question addressed the effect of the treatment on the speed of recognition and production of English refusals by the participants. Repeated measure ANOVAs and one-way ANOVAs were computed to investigate this research question. The descriptive statistics of the PLJT and ODCT speech rate scores over the three testing periods are demonstrated in Table 3, Figure 3 and 4.

Table 3

Descriptive statistics of the speech rate

\begin{tabular}{|c|c|c|c|c|c|c|c|c|}
\hline \multirow{2}{*}{ Instrument } & \multirow{2}{*}{ Group } & \multirow[b]{2}{*}{$\mathrm{N}$} & \multicolumn{2}{|c|}{ Pretest (1) } & \multicolumn{2}{|c|}{ Posttest (2) } & \multicolumn{2}{|c|}{ Delayed posttest (3) } \\
\hline & & & $\mathrm{M}$ & SD & $\mathrm{M}$ & SD & $\mathrm{M}$ & $\mathrm{SD}$ \\
\hline \multirow{2}{*}{$\begin{array}{l}\text { PLJT } \\
\text { (Recognition) }\end{array}$} & Experimental & 35 & 5.19 & 1.24 & 4.11 & 1.46 & 3.04 & 1.92 \\
\hline & Control & 37 & 5.21 & 1.53 & 5.16 & 1.35 & 4.81 & 1.38 \\
\hline \multirow{2}{*}{$\begin{array}{l}\text { ODCT } \\
\text { (Production) }\end{array}$} & Experimental & 35 & 10.42 & 5.37 & 11.15 & 4.32 & 14.02 & 3.71 \\
\hline & Control & 37 & 10.04 & 4.83 & 10.52 & 4.14 & 10.95 & 4.23 \\
\hline
\end{tabular}

The results of one-way ANOVAs on the pretest speed scores showed that the two groups were not significantly different before the experiment $(p>.05)$. In order to compare the scores over the three testing sessions, repeated measures ANOVAs were used. Results showed significant developments in the speedy recognition of refusals, $F(3,35)=3.41, p<.05$. Additionally, post hoc Tukey tests detected that the scores 
Shirinbakhsh, S., Eslami Rasekh, A., \& Tavakoli, M.

reduced significantly from pretest to posttest and then to delayed posttest $(p<.05)$. Moreover, one way ANOVAs across the two groups demonstrated that learners in the experimental group recognized significantly faster than their counterparts in the control group in both Time $1, F(2,72)=7.65, p<.05$, and Time $2, F(2,72)=8.12, p$ $<.05$.

Regarding the ODCT speech rate scores (see Figure 3), repeated measures ANOVA revealed that there was a significant improvement in the learners over time, $F(3,35)=8.19, p<.05$. However, post hoc comparisons showed that there was only a significant difference between the first and last testing sessions $(p<.05)$. In addition, one-way ANOVAs revealed significant differences between the experimental and control groups only in the third testing session, $F(2,72)=11.21, p<.05$. The analysis showed no other significant group differences.

In sum, these results suggested that input-based practice helped to improve the recognition speed of the English refusals. In addition, the findings demonstrated that although the speed of production did not develop in shorter time (i.e., Time 1 to 2), a more steady improvement was achieved over longer time periods (i.e., Time 1 to 3$)$.

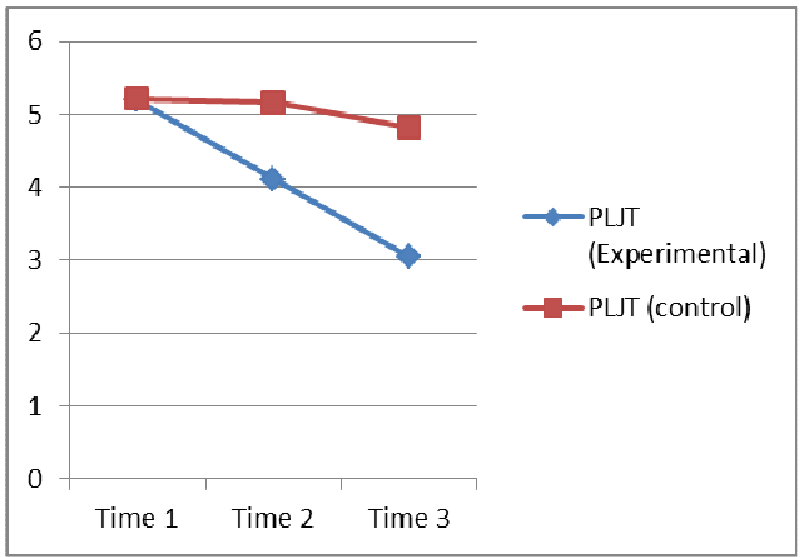

Figure 3. Development of the Speed of Recognition

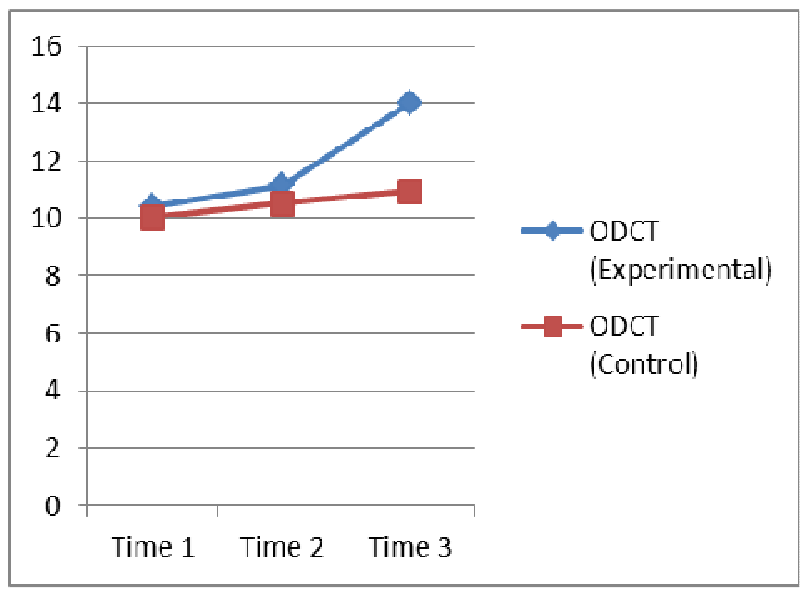

Figure 4. Development of the Speed of Production

\subsection{Relationships among general proficiency, lexical access ability, pragmatic recognition and production}

The third research question addressed the extent to which proficiency and lexical access ability were related to the pragmatic accuracy and speed of Iranian EFL learners' recognition and oral production of English refusals. To study these relationships, Pearson product-moment correlation coefficient was conducted. Before calculating the correlations, initial analyses were performed to ensure no violation of the assumptions of normality, linearity and homoscedasticity. Afterwards, correlation analyses were used to examine the relationships between the 
The effect of input-based practice on the accurate and speedy performance of EFL refusals

variables, the results of which are presented in Table 4.

\section{Table 4}

Pearson product-moment correlation coefficient

\begin{tabular}{llcc}
\hline & & Proficiency & Lexical Access Ability \\
\hline PLJT & Pearson Correlation & $.349^{*}$ & -.072 \\
Accuracy & Sig. (2-tailed) & .035 & .548 \\
(Recognition) & $\mathrm{N}$ & 72 & 72 \\
\hline ODCT & Pearson Correlation & $.275^{*}$ & -.012 \\
Accuracy & Sig. (2-tailed) & .020 & .920 \\
(Production) & $\mathrm{N}$ & 72 & 72 \\
\hline PLJT & Pearson Correlation & -.163 & $.374^{*}$ \\
Speed & Sig. (2-tailed) & .170 & .005 \\
(Recognition) & $\mathrm{N}$ & 72 & 72 \\
\hline ODCT & Pearson Correlation & .168 & $-.257^{*}$ \\
Speed & Sig. (2-tailed) & .159 & .031 \\
(Production) & $\mathrm{N}$ & 72 & 72
\end{tabular}

As presented in Table 4, the results of the correlation coefficient revealed that there was a positive and significant correlation between the general proficiency and the pragmatic accuracy of recognition $(r=.349, p$ $<.05)$ as well as production $(r=.275, p<.05)$ of English refusals. Cohen $(1988$, pp. 79-81) suggested the following guidelines: small $r=.10$ to .29 ; medium $r=.30$ to .49 ; large $r=.50$ to 1.0. Thus, as for the current study, there was a medium correlation between the proficiency and the accuracy of recognition ( $r$ is above .29); while, the relationship between proficiency and accuracy of production was small ( $r$ is below .29).

In addition, the results illustrated in Table 4 showed that there was a moderate and positive correlation between the lexical access ability and pragmatic recognition speed $(r=.374, p<.05)$. Moreover, findings indicated a small and negative relationship between lexical access ability and pragmatic production speed ( $r=$ $-.257, p<.05)$. As is clear in Table 4, the correlation coefficient revealed no significant relationships between lexical access ability and the pragmatic accuracy.

Consequently, the above results suggested that more proficient learners could achieve higher pragmatic accuracy in their recognition and production of refusals; whereas, those who were quicker in their lexical access ability were faster in both the recognition and production of English refusals as well.

\section{Discussion}

This study was set out with the purpose of examining the effects of an instruction, general language proficiency and a cognitive processing skill on pragmatic recognition and oral production of EFL learners. In other words, this study intends to find the impact input-based practice, language proficiency and lexical access ability (LAT) may have on the accurate and speedy recognition and production of English refusals. The results revealed the positive effect of input-based practice in speedy recognition and accurate production of English refusals. In addition, language proficiency and LAT were found to correlate significantly with pragmatic accuracy and pragmatic speed, respectively.

The results of PLJT for the accurate pragmatic recognition (declarative knowledge) were not significant in all the three tests: pre-, post- and delayed posttests. That is, input-based practice could not improve the accuracy of learners in the recognition of pragmatically appropriate and grammatically accurate English refusals. Even their scores did not show any improvement over control group. This could be explained by the lack of grammatical exercises during instruction (Li, 2012). Learners' attention was drawn to the accuracy and appropriateness of pragmatic utterances in the dialogues and there was no focus on the accuracy of grammar.

Although PLJT did not show any significant effect of practice on the accurate pragmatic recognition, the 
ODCT revealed a significant impact of practice on accurate pragmatic production. The ODCT's scores increased significantly after the treatment. More specifically, the input-based practice managed to improve learners' pragmatically appropriate and grammatically accurate production of refusals from pretest to posttest and help them keep the advantages. The results are in line with Li's $(2012)$ and Takimoto's $(2008,2009)$ studies that practice on input-based activities improve pragmatically accurate productions.

Another interesting finding is the development of the learners' score in pragmatic recognition speed (procedural knowledge). Their speed rate reduction from 5.19 to 3.04 seconds in delayed posttest points to the success of input-based practice in transforming declarative knowledge to procedural knowledge. This could be explained by the skill acquisition theory (ACT-R model) and, also, by the method of instruction employed in input-based practice. According to the skill acquisition theory, the increased practices between the input and the cognitive processes lead to the improvement of pragmatic recognition speed (Anderson, 1990). Learners in the treatment group were exposed to 16 practice items in 4 sessions. In each time, they had to 'identify' pragmatically appropriate refusals. This repeated 'identification' activity might fortify pragmatic procedural knowledge in the receptive task of PLJT. Therefore, it might give the learners enough opportunity to transfer their declarative knowledge of refusal to more proceduralized one.

The results of ODCT did not yield a considerable gain in pragmatic speed production. While the production speed scores from pretest to delayed posttest was significant, their effect from pretest to posttest was negligible. It seemed the repeated input-based practice of refusal could not lead to the improvement of pragmatic production speed in five treatment sessions. Once more, these results are explainable by ACT-R model. The main emphasis of input-based practice was on the receptive skill of recognition (the repetitive identification of refusal activities), and pragmatic production speed got no skill-based practice. Therefore, the ODCT did not reveal much significant gains from pretest to posttest in learners' speed production. The above findings corroborate Li and Taguchi (2014) and DeKeyser (2007, 2009) studies that the development of processing speed requires skill-specific practice modality. That is input-based practice would result in the development of recognition speed not production speed.

To examine the potential effect of underlying factors on the pragmatic accuracy and performance speed, this study addressed the relationship among language proficiency- measured by OPT- and lexical access ability measured by lexical access test (LAT)-, on one hand; as well as pragmatic accuracy and pragmatic speed. The finding indicated a significant relation between proficiency and pragmatic accuracy. The more proficient learners could achieve higher pragmatic accuracy in their recognition and production of refusals. However, proficiency had no significant relationship with the pragmatic speed in neither recognition nor production.

Regarding LAT and pragmatic speed, it should be noted that in pragmatic recognition, the amount of time it took for each learner to complete the task of PJLT was counted for recognition speed. Therefore, the less time indicated faster recognition. In addition, the less time spent for the completion of LAT showed faster cognitive processing ability. Thus, the findings lead to a positive correlation between LAT and recognition speed. On the other hand, to calculate pragmatic production speed, the average number of words spoken in one minute was considered. So, more words showed faster production; however, in LAT less time indicated quicker production. As a result, LAT and pragmatic production found to have negative correlation. Lexical access ability, nonetheless, bore no relationship to pragmatic accuracy. Namely, the fast cognitive processing ability was not related to the accurate and appropriate knowledge of refusals. The results corroborate Taguchi $(2007,2008)$ findings that pragmatic speed is a result of efficient processing ability and it is not related to pragmatic knowledge. Performance speed subsumes the coordination of some constituent components including cognitive, linguistic and sociocultural components which must operate automatically and efficiently to gain speedy pragmatic performance (Segalowitz, 2000, 2003). Since lexical access ability form one of those components, it directly contributes to performance speed. This finding suggests that learner' cognitive speed and readiness in categorizing each single word in LAT is related to the advancement in pragmatic speed performance. These results further support the duality of pragmatic competence with pragmatic knowledge and speed as its 
components.

\section{Conclusion}

The primary purpose of present study was to examine the effect of input-based practice on the pragmatic accuracy and speed of Iranian EFL learners' recognition and oral production of English refusals. It further explored the extent to which proficiency and lexical access ability are related to the pragmatic accuracy and speed of Iranian EFL learners' recognition and oral production of English refusals. Generally, the study demonstrated that an ACT-R based instruction -input-based practice- was successful in the improvement of accurate production and speedy recognition of English refusal. The results, also, support the distinction between pragmatic knowledge and pragmatic performance speed. The research, further, highlighted the positive correlation between pragmatic accuracy and proficiency, on one hand and pragmatic speed and lexical access ability, on the other hand.

The study suggests some insights for teaching English as a foreign language. First, language teachers can benefit from the application of ACT-R model in the form of repeated practice in their classroom. Their students would gain considerable results from repetitive focused practice in their comprehension and production of pragmatic features. Second, considering the positive relationship between lexical ability and pragmatic speed, language teachers might be interested in the application of fluency exercises which involves repetitions with a focus on the form and its meaning. These low level cognitive exercises prepare the learners for higher cognitive processes in their language training experience such as pragmatic performance speed. Finally, the significant effect of proficiency on pragmatic accuracy points to the usefulness of input-based instruction for low proficient learners. The instruction exceeds the learning of pragmatic features.

\section{References}

Al-Issa, A. (2003). Sociocultural transfer in L2 speech behaviors: Evidence and motivating factors. International Journal of Intercultural Relations, 27(5), 581-601. http://dx.doi.org/10.1016/S0147-1767(03)00055-5

Anderson, J. R. (1983). The architecture of cognition. Cambridge: Psychology Press.

Anderson, J. R. (1990). Cognitive psychology and its implications: WH Freeman/Times Books/Henry Holt \& Co.

Beebe, L., Takahashi, T., \& Uliss-Weltz, R. (1990). Pragmatic transfer in ESL refusals. In R. Scarcella, E. Anderson \& S. Krashen (Eds.), Developing Communication Competence in a Second Language. (pp. 55-73). New York: Newbury House.

Chen, H. J. (1996). Cross-Cultural Comparison of English and Chinese Metapragmatics in Refusal. Indiana University.

Cohen, J. W. (1988). Statistical power analysis for the behavioral sciences. Hillsdale, NJ: Lawrence Erlbaum Associates.

DeKeyser, R. (2007). Skill Acquisition Theory. In B. VanPatten \& J. Williams (Eds.), Theories in second language acquisition: An introduction (pp. 94-113). New York: Routledge.

DeKeyser, R. (2009). Cognitive-psychological processes in second language learning. In M. H. Long \& C. J. Doughty (Eds.), The handbook of language teaching (pp. 119-138). Malden, MA: Blackwell. http://dx.doi.org/10.1002/9781444315783.ch8

Ebsworth, M. E., \& Kodama, N. (2011). The pragmatics of refusals in English and Japanese: Alternative approaches to negotiation. International Journal of the Sociology of Language, 2011(208), 95-117. http://dx.doi.org/10.1515/ijs1.2011.014

Francis, W. S., Tokowicz, N., \& Kroll, J. F. (2014). The consequences of language proficiency and difficulty of lexical access for translation performance and priming. Memory \& Cognition, 42(1), 27-40. http://dx.doi.org/10.3758/s13421-013-0338-1

Gutiérrez, E., Müller, O., Baus, C., \& Carreiras, M. (2012). Electrophysiological evidence for phonological priming in Spanish Sign Language lexical access. Neuropsychologia, 50(7), 1335-1346. 
Shirinbakhsh, S., Eslami Rasekh, A., \& Tavakoli, M.

http://dx.doi.org/10.1016/j.neuropsychologia.2012.02.018

Hashemian, M. (2012). Cross-Cultural Differences and Pragmatic Transfer in English and Persian Refusals. Journal of Teaching Language Skills, 4(3), 23-46.

Kasper, G. (2001). Four perspectives on L2 pragmatic development. Applied Linguistics, 22(4), 502-530. http://dx.doi.org/10.1093/applin/22.4.502

Li, S. (2012). The Effects of Input-Based Practice on Pragmatic Development of Requests in L2 Chinese. Language Learning, 62(2), 403-438. http://dx.doi.org/10.1111/j.1467-9922.2011.00629.x

Li, S., \& Taguchi, N. (2014). The Effects of Practice Modality on Pragmatic Development in L2 Chinese. The Modern Language Journal, 98(3), 794-812. http://dx.doi.org/10.1111/modl.12123

Poulin-Dubois, D., Bialystok, E., Blaye, A., Polonia, A., \& Yott, J. (2013). Lexical access and vocabulary development in very young bilinguals. International Journal of Bilingualism, 17(1), 57-70. http://dx.doi.org/10.1177/1367006911431198

Salazar Campillo, P., Safont Jordà, M. P., \& Codina Espurz, V. (2009). Refusal strategies: A proposal from a sociopragmatic approach. RacL: Revista Electrónica de Lingüística Aplicada, 8, 139-150.

Schmidt, R. (1993). Consciousness, learning and interlanguage pragmatics. In G. Kasper \& S. Blum-Kulka (Eds.), Interlanguage pragmatics (pp. 43-57). NewYork: Oxford University Press.

Seabrook, E., Brown, G. D. A., \& Solity, J. E. (2005). Distributed and massed practice: From laboratory to classroom. Applied Cognitive Psychology, 19, 107-122. http://dx.doi.org/10.1002/acp.1066

Segalowitz, N. (2000). Automaticity and attentional skill in fluent performance. In H. Riggenbach (Ed.), Perspectives on fluency (pp. 200-219). Ann Arbor: University of Michigan.

Segalowitz, N. (2003). Automaticity and second languages. In C. Doughty \& M. Long (Eds.), The handbook of second language acquisition (pp. 382-408). Malden, MA: Blackwell. http://dx.doi.org/10.1002/9780470756492.ch13

Segalowitz, N., \& Freed, B. F. (2004). Context, contact, and cognition in oral fluency acquisition: Learning Spanish in at home and study abroad contexts. Studies in second language acquisition, 26(02), 173-199. http://dx.doi.org/10.1017/S0272263104262027

Taguchi, N. (2005). Comprehending implied meaning in English as a foreign language. The Modern Language Journal, 89(4), 543-562. http://dx.doi.org/10.1111/j.1540-4781.2005.00329.x

Taguchi, N. (2007). Development of speed and accuracy in pragmatic comprehension in English as a foreign language. Tesol Quarterly, 41(2), 313-338. http://dx.doi.org/10.1002/j.1545-7249.2007.tb00061.x

Taguchi, N. (2008). Cognition, language contact, and the development of pragmatic comprehension in a studyabroad context. Language Learning, 58(1), 33-71. http://dx.doi.org/10.1111/j.1467-9922.2007.00434.x

Taguchi, N. (2011). Teaching pragmatics: Trends and issues. Annual Review of Applied Linguistics, 31, 289-310. http://dx.doi.org/10.1017/S0267190511000018

Taguchi, N. (2013). Refusals in L2 English: Proficiency effects on appropriateness and fluency. In O. Martí-Arnándiz \& P. Salazar-Campillo (Eds.), Refusals in instructional contexts and beyond (Vol. 25, pp. 101-119). Amsterdam/New York, NY: Rodopi.

Takimoto, M. (2008). The effects of deductive and inductive instruction on the development of language learners' pragmatic competence. The Modern Language Journal, 92(3), 369-386. http://dx.doi.org/10.1111/j.1540-4781.2008.00752.x

Takimoto, M. (2009). The effects of input-based tasks on the development of learners' pragmatic proficiency. Applied Linguistics, 30(1), 1-25. http://dx.doi.org/10.1093/applin/amm049

Umale, J. (2011). Pragmatic Failure in Refusal Strategies: British versus Omani Interlocutors. Arab World English Journal, 2(1), 18-46.

Usó-Juan. (2013). Effects of metapragmatic instruction on EFL learners' production of refusals. In O. Martí-Arnándiz \& P. Salazar-Campillo (Eds.), Refusals in instructional contexts and beyond (Vol. 25, pp. 65-99).

Wong, W. (2004). The Nature of Processing Instruction. In B. VanPatten (Ed.), Processing instruction: Theory, research, and commentary (pp. 33-63). Mahwah, NJ: Erlbaum. 


\section{Appendices}

Appendix A: Taxonomy on the Speech Act of Refusing (From Salazar, Safont and Codina, 2009, p. 145).

\section{REFUSALS}

Direct Strategies

1. Bluntness- No. / I refuse.

2. Negation of proposition - I can't, I don't think so.

Indirect Strategies

1. Plain indirect-It looks like I won't be able to go.

2. Reason/Explanation- I can't. I have a doctor's appointment.

3. Regret/Apology- I'm so sorry! I can't.

4. Alternative:

- Change option- I would join you if you choose another restaurant.

- Change time (Postponement)- I can't go right now, but I could next week

5. Disagreement/Dissuasion/ Criticism- Under the current economic circumstances, you should not be asking for a rise right now!

6. Statement of principle/philosophy- I can't. It goes against my beliefs!

7. Avoidance

- Non-verbal: Ignoring (Silence, etc.)

- Verbal:
○ Hedging- Well, I'll see if I can.
- Change topic
○ Joking
○ Sarcasm

\section{ADJUNCTS TO REFUSALS}

1. Positive opinion- This is a great idea, but...

2. Willingness- I'd love to go, but...

3. Gratitude- Thanks so much, but...

4. Agreement- Fine!, but...

5. Solidarity/Empathy- I'm sure you'll understand, but... 
Shirinbakhsh, S., Eslami Rasekh, A., \& Tavakoli, M.

Appendix B: Interactive Six-Item Written DCT (SAMPLE) (adapted from Al-Issa, 2003; Beebe et al., 1990; Ebsworth \& Kodama, 2011; Umale, 2011)

Student name:.....

Directions: Please read the following six situations. After each situation, you are asked to write a response in the blank after "you." Respond as you would in an actual conversation.

1. You are working in a college. You are unmarried and one of your married colleagues who has a big family comes to your house to borrow money.

Colleague: I have a big family and I just don't know where the money goes. The children always need something or the other. Could you lend me 500,000 Toman for a month?

You:

Colleague: It's O.K. I'll borrow from someone else.

2. Your friend invites you on telephone, for dinner and a magic show at a hotel.

Friend: We have arranged a get-together at Abbassi Hotel. There would be dinner and magic show for children. You are invited to join us.

You:

Friend: Well, I can understand your position.

\section{Appendix C: Referential and Affective Activities (adapted from Chen, 1996; Usó-Juan, 2013)}

\section{WORKSHEET 1(SAMPLE)}

\section{Part one}

Read the following communicative situations. Identify the social distance and power to each situation and tick $(\sqrt{ })$ whether the rejection is appropriate or inappropriate.

1. You are a student at a University. You are about to go home in your car. Another student, whom you have never met before, approaches you and asks you for a lift home saying that you both live in the same area of the city. You refuse by saying:

- I'm sorry, but I am not going straight home. There are quite a few things I need to do before heading home! Perhaps another day.

Social distance: close

Distant

Very distant

Pragmatically appropriate $\square$
Power: speaker= hearer

Speaker $>$ hearer

Speaker $<$ hearer

Pragmatically inappropriate $\square$

2. You are a student in a Business studies class at the university. One of your lecturers asks you to pick him/her up every day from his/her home, saying that his/her house is near yours. You refuse by saying:

- No, I can't. I always have things to attend to before classes.

Social distance: close

Distant

Very distant

Pragmatically appropriate $\square$
Power: speaker $=$ hearer

$$
\text { Speaker }>\text { hearer }
$$

Speaker $<$ hearer

Pragmatically inappropriate $\square$ 
The effect of input-based practice on the accurate and speedy performance of EFL refusals

Part two

Give each response in each situation a rating, by circling one of the five numbers on the scale besides it.

Very inappropriate Inappropriate Undecided Appropriate Very appropriate

$\begin{array}{lllll}1 & 2 & 3 & 4 & 5\end{array}$

3. W attends classes regularly and takes good notes. One person in W's class who doesn't show up very often asks to borrow W's notes. Since W has to compete with the rest of the class to earn a good grade, W doesn't feel like sharing the results of his/her hard work with someone who doesn't work for it. W says:

\begin{tabular}{llllll}
\hline A) "If I lend my notes to you, it is unfair to me and others who come to class regularly." & 1 & 2 & 3 & 4 & 5 \\
B) "I think you should think about what you are doing." & 1 & 2 & 3 & 4 & 5 \\
C) "I need them to study from. Maybe someone in your study group can loan you the notes. & 1 & 2 & 3 & 4 & 5
\end{tabular}
Sorry."

4. A friend invites $X$ to dinner, but $X$ really can't stand this friend's husband/wife. $X$ says:

\begin{tabular}{|c|c|c|c|c|}
\hline A) "Well, I can't that night. But, could we go to lunch Tuesday together?" & 1 & 3 & 4 & 5 \\
\hline B) "I don't want to go out at night." & 1 & 3 & 4 & 5 \\
\hline $\begin{array}{l}\text { C) "You know I don't get along with your husband/wife. It'll be awkward when we are } \\
\text { together." }\end{array}$ & 1 & & 4 & 5 \\
\hline
\end{tabular}

\section{Appendix D: Pragmatic Listening Judgment Task (PLJT) (adapted from Beebe et al., 1990; Chen, 1996; Umale, 2011; Usó-Juan, 2013) (SAMPLE)}

1. You are the boss of a company. Your employee wants to invite you for his daughter's birthday.

Employee: I've arranged a small party for my daughter's birthday at home on Monday and I would be delighted if you could come along. You refuse by saying:

'Thank you for the invitation. I have a business trip on Monday otherwise I would be delighted.'

A. Pragmatically appropriate and grammatically accurate.
B. Pragmatically inappropriate and grammatically accurate.
C. Pragmatically appropriate and grammatically inaccurate.

2. Your close friend asks to use your home while you are on holiday for one week. Knowing that he/she is a messy person, you don't want to let him/her use your home for a week. You refuse by saying:

'To be quite honest, I really don't feel comfortable with letting you use my home.

It's not fair to see my home in a mess when I come back. You always try to get benefit from someone else's assets.'
A. Pragmatically appropriate and grammatically accurate.
B. Pragmatically inappropriate and grammatically accurate.
C. Pragmatically appropriate and grammatically inaccurate. 
1. You are an English teacher in a language school. One of your colleagues can't attend one of his classes. The manager asks you to handle the class instead of him but you've already planned to do something.

Manager: Mr./Ms. Karimi has a very important exam tomorrow, and he is not well-prepared. Could you handle his class this afternoon please? You refuse by saying:

2. You are a research student at University. You go to a cafeteria, where you have never been before, to buy a doughnut. Since you don't know the exact price of the doughnut you have only brought a 5000 toman note. When you are about to pay, the waitress tells you it costs 250 tomans and asks you if you could give him/her the exact amount of money since he/she only has money in the form of notes. You refuse by saying:

Appendix F: Accuracy Rating Scale

\begin{tabular}{|ll|l|}
\hline \multicolumn{2}{|l|}{ Ratings } & Descriptors \\
\hline 5 & Excellent & $\begin{array}{l}\text { - Expressions are fully appropriate for the situation. } \\
\text { - No or almost no grammatical and discourse errors. }\end{array}$ \\
\hline 4 & Good & $\begin{array}{l}\text { - Expressions are mostly appropriate. } \\
\text { - Very few grammatical and discourse errors. }\end{array}$ \\
\hline 3 & Fair & $\begin{array}{l}\text { - Expressions are only somewhat appropriate. } \\
- \text { Grammatical and discourse errors are noticeable, but they do not interfere } \\
\text { with appropriateness. }\end{array}$ \\
\hline 2 & Poor & $\begin{array}{l}- \text { Due to the interference from grammatical and discourse errors, } \\
\text { appropriateness is difficult to determine. }\end{array}$ \\
\hline 1 & Very poor & $\begin{array}{l}\text { - Expressions are very difficult or too short to understand. There is no evidence } \\
\text { that the intended speech acts are performed. }\end{array}$ \\
\hline 0 & & \begin{tabular}{l}
- No performance \\
\hline
\end{tabular}
\end{tabular}

\section{Appendix G: Lexical Access Test (taken from Segalowitz \& Freed, 2004)}

Animate:

actor, adult, ant, bear, bee, bird, boy, bride, brother, cat, child, cow, dancer, daughter, dentist, doctor, dog, duck, farmer, father, female, girl, goat, horse, human, husband, judge, king, lady, maple, monkey, mother, mouse, nephew, nurse, oak, parent, person, pig, rabbit, rat, secretary, sheep, snake, son, student, teacher, tiger, tree, turtle, wife, wolf, woman

Inanimate:

basket, belt, bench, bicycle, blanket, board, boat, book, building, car, chair, chimney, clothes, comb, desk, dictionary, door, fireplace, floor, garbage, ink, job, key, kitchen, knife, lamp, luggage, medal, newspaper, pants, pencil, perfume, picture, pillow, plane, road, roof, ship, sink, spoon, stamp, step, street, tape, television, tire, trophy, truck, tunnel, umbrella, wall, wallet, window 